\title{
Precarização laboral e saúde de trabalhadores terceirizados em uma instituição pública de ensino
}

\author{
Precarious employment and health of outsourced workers in a public educational institution \\ Empleo precario y salud de los trabajadores subcontratados en una institución educativa pública
}

Recebido: 25/01/2022 | Revisado: 29/01/2022 | Aceito: 05/02/2022 | Publicado: 09/02/2022

Pamella Beserra de Melo

ORCID: https://orcid.org/0000-0003-0255-4122 Universidade Federal do Rio Grande do Norte, Brasil

E-mail: pambmelo@gmail.com

Cássio Adriano Braz de Aquino ORCID: https://orcid.org/0000-0001-8651-1634 Universidade Federal do Ceará, Brasil E-mail: brazaquino@ufc.br

Francisco Pablo Huascar Aragão Pinheiro

ORCID: https://orcid.org/0000-0001-9289-845X Universidade Federal do Ceará, Brasil E-mail: pablo.pinheiro@ufc.br

Nara Maria Forte Diogo Rocha ORCID: https://orcid.org/0000-0001-5040-1492 Universidade Federal do Ceará, Brasil E-mail: narafdiogo@gmail.com

Antonio Renan Santana

ORCID: https://orcid.org/0000-0003-3408-7995 Universidade Federal do Ceará, Brasil

E-mail: antoniorenan@outlook.com

Louanne Carneiro de Oliveira

ORCID: https://orcid.org/0000-0003-1354-2995 Universidade Federal do Ceará, Brasil E-mail: louanne.anne@gmail.com

Gabriele Sousa Costa

ORCID: https://orcid.org/0000-0003-2905-4144 Universidade Federal do Ceará, Brasil E-mail: gabrielesousa@alu.ufc.br

Taiza Pereira Aguiar

ORCID: https://orcid.org/0000-0002-3157-5961 Universidade Federal do Ceará, Brasil E-mail: taizaguiar@alu.ufc.br

\begin{abstract}
Resumo
A terceirização se insere no processo de precarização do trabalho e pode ser definida como um procedimento no qual uma atividade é efetivada para uma organização, todavia, a contratação dos profissionais se dá por meio de uma empresa interposta. A pesquisa teve como objetivo analisar o ofício e a saúde de trabalhadores terceirizados $(n=10)$ que atuavam no setor de almoxarifado de uma instituição pública de ensino. O referencial teórico e metodológico da investigação veio da Clínica da Atividade. Foi realizado um estudo de caso a partir de dados provenientes de uma intervenção. Utilizou-se a análise construtivo-interpretativa sobre os conteúdos dos registros produzidos durante a intervenção. Os resultados indicaram diferenças de remuneração e de benefícios. Também foram constatadas condições de trabalho inadequadas: ambiente com estrutura precária; exposição a produtos perigosos e equipamentos inapropriados. Observou-se, ainda, o autoritarismo e as atitudes centralizadoras de um gestor, o que reduzia a autonomia dos trabalhadores e os submetia a situações vexatórias. Conclui-se que esses profissionais estão mais sujeitos a acidentes, doenças, assédio, ameaças, desrespeito e preconceito devido à condição de trabalho precarizada.
\end{abstract}

Palavras-chave: Terceirização; Trabalho; Saúde.

\begin{abstract}
Outsourcing is part of the job insecurity process and can be defined as a procedure in which an activity is carried out for an organization, however, the hiring of professionals occurs through an intermediary company. The research aimed to analyze the work and the health of outsourced workers $(n=18)$ who worked in the warehouse sector of a public educational institution. The theoretical and methodological framework of the investigation came from the Clinic of Activity. A case study was carried out using data from an intervention. Constructive-interpretative analysis was used
\end{abstract}


on the contents of the records produced during the intervention. The results indicated differences in remuneration and benefits. Inadequate working conditions were also found: environment with poor structure; exposure to dangerous products and inappropriate equipment. It was also observed the authoritarianism and centralizing attitudes of a manager, which reduced workers' autonomy and subjected them to vexing situations. It was concluded that these professionals are subject to accidents, diseases, harassments, threats, disrespect and prejudice due to precarious work conditions.

Keywords: Outsourced services; Work; Health.

\section{Resumen}

La subcontratación forma parte del proceso de trabajo precario y puede definirse como un procedimiento en el que se realiza una actividad para una organización, sin embargo, la contratación de profesionales se realiza a través de una empresa intermediaria. La investigación tuvo como objetivo analizar la ocupación y salud de los trabajadores subcontratados $(n=10)$ que laboraban en el sector de almacenes de una institución educativa pública. El marco teórico y metodológico de la investigación provino de Clínica da Atividade. Se realizó un estudio de caso utilizando datos de una intervención. Se utilizó el análisis constructivo-interpretativo del contenido de los registros producidos durante la intervención. Los resultados indicaron diferencias en remuneraciones y beneficios. También se encontraron condiciones de trabajo inadecuadas: ambiente con estructura precaria; exposición a productos peligrosos y equipos inapropiados. También se observó el autoritarismo y las actitudes centralizadoras de un directivo, que redujeron la autonomía de los trabajadores y los sometieron a situaciones vejatorias. Se concluye que estos profesionales están más sujetos a accidentes, enfermedades, hostigamientos, amenazas, irrespetos y prejuicios por las precarias condiciones laborales.

Palabras clave: Subcontratación; Trabajo; Salud.

\section{Introdução}

Trabalhadores terceirizados têm piores condições laborais e são mais vulneráveis a acidentes e a doenças decorrentes do trabalho quando comparados a profissionais contratados diretamente. A terceirização de mão-de-obra se insere no processo de precarização do trabalho que, a partir dos anos 70, ganhou forma através das transformações sofridas no padrão de produção capitalista, que não estava mais restrito ao binômio do taylorismo-fordismo e adotou novos processos de acumulação, como o toyotismo (Antunes, 1999).

Tais modificações promoveram mudanças no mundo do trabalho que, segundo Aquino (2008), foi reestruturado e adotou o discurso da flexibilização, o que fragilizou os vínculos laborais, comprometeu as formas de inserção e permanência no trabalho, bem como aumentou a vulnerabilidade a direitos e garantias sociais básicas. Nesse sentido, Druck (2011) reforça que as atuais formas de inserção no mundo do trabalho enfraquecem o suporte e a manutenção dos direitos sociais dos trabalhadores. Ela aponta, também, os fenômenos de intensificação e terceirização do trabalho como modalidades de precarização laboral.

Nesse contexto, a terceirização pode ser definida como um processo no qual a atividade é efetivada para uma organização, todavia a contratação do trabalhador se dá por meio de uma outra empresa que se interpõe nessa relação. O que se pretende é a transferência de riscos e de parte das despesas com a contratação de mão-de-obra (Marcelino, 2007). Há, desta forma, uma diminuição dos custos com a força de trabalho, pois a relação estabelecida deixa de ser trabalhista (entre trabalhador e empresa) e se torna mercantil (entre empresas) (Marcelino \& Cavalcante, 2012).

A terceirização se consolida no contexto de reestruturação produtiva do capitalismo mundializado, no qual, em um modelo de acumulação flexível, as empresas se desresponsabilizam por alguns serviços ou mesmo por parte da produção, tendo em vista a redução de despesas (Druck \& Borges, 2002; Druck, 2016a). Segundo Druck (2016b, 2016c), a terceirização constituise como uma forma de a política neoliberal atacar o Estado social e democrático. Tal situação se torna ainda mais grave em um país como o Brasil, em que não se desenvolveu uma estrutura social baseada no trabalho assalariado, de modo que houvesse garantia de direitos aos trabalhadores e uma rede de proteção social plenamente instituída (Gimenez \& Krein, 2016). Batista et al. (2021) afirmam que a precarização das relações de trabalho é uma estratégia para aumentar a lucratividade das empresas, a partir da degradação das condições de trabalho, da imposição de jornadas exaustivas, dentre outras.

A terceirização no setor público brasileiro tem início durante a ditadura militar e ganha maior centralidade durante o governo Fernando Henrique Cardoso, a partir da proposta de Reforma do Estado. Neste período, estabeleceu-se uma limitação 
inicial de que somente atividades compreendidas como acessórias poderiam ser terceirizadas. Todavia, mudanças nas carreiras do funcionalismo público que extinguiram diversos cargos e a possibilidade de realização de atividades-fim por meio da contratação de Organizações Sociais acabaram por abrir espaço para a terceirização de forma ampla (Druck et al., 2018).

Quando comparados a empregados de empresas que realizam contratações diretas, os trabalhadores terceirizados brasileiros têm alta rotatividade e, ainda, um tempo médio de vinculação ao emprego menor. Também se observa uma maior jornada de trabalho e uma remuneração inferior. Vê-se, ainda, um maior índice de afastamento do trabalho por acidentes típicos (Druck, 2016a; Secretaria Nacional de Relações de Trabalho [SNRT], 2014; Pelatieri, 2018) e taxas superiores de doenças ocupacionais (Druck, 2016c).

O discurso da flexibilidade associado à terceirização leva a uma transferência para os trabalhadores da responsabilidade sobre sua formação e sua qualificação profissionais (Lima, 2010; de Magalhães et al., 2013). Dentro das organizações, também são observadas diferenças de tratamento entre empregados diretos e terceirizados que se manifestam, por exemplo, em piores condições laborais e menor acesso a benefícios (Lima, 2010). Cria-se, desta maneira, uma cisão entre trabalhadores de primeira e segunda classe, o que fragmenta a identidade dos coletivos de trabalho (Druck, 2016a). A terceirização também é associada à perda de direitos, assim como a uma situação de instabilidade na qual os profissionais são humilhados e desvalorizados (Druck, 2002).

Diversos estudos tematizam empregados terceirizados que atuam em instituições públicas de ensino e enfocam os trabalhadores dos serviços de limpeza (Andrade et al., 2016; Barbati et al., 2016; Berni et al., 2016; Gemma et al., 2017; Guimarães \& Ferreira, 2018; Neves et al., 2013) e, em alguns casos, de vigilância (Neves et al., 2013) e de almoxarifado (Guimarães \& Ferreira, 2018). Tais investigações mostram que formas de adoecimento físico ou psíquico, redução da capacidade de trabalho, além de outros prejuízos, estão ligados a condições de trabalho impróprias, como insuficiência ou inadequação de materiais e equipamentos de proteção individuais (Andrade et al., 2016; Neves et al., 2013). Tais questões também estão vinculadas aos baixos salários, à instabilidade no emprego e a longos períodos sem férias devido à rotatividade das empresas contratantes (Andrade et al., 2016).

Ainda, em relação às investigações apontadas acima, aspectos da organização do trabalho também se apresentam como negativos quando se observa pressão por resultados, normas rígidas, mudanças de setor, trocas de turno de trabalho (Neves et al., 2013) e número insuficiente de empregados para o volume de atividades (Gemma et al., 2017). Falta de reconhecimento profissional (Andrade et al., 2016; Barbati et al., 2016; Gemma et al., 2017; Guimarães \& Ferreira, 2018), sentimentos de inferioridade pelo tipo de atividade exercida (Neves et al., 2013) e relacionamentos negativos com as chefias (Berni et al., 2016; Guimarães \& Ferreira, 2018; Neves et al., 2013) e, em alguns contextos, casos de assédio moral (Barbati et al., 2016); também são vistos como promotores de prejuízos aos trabalhadores.

Em pesquisa com trabalhadores terceirizados de um órgão público, Barbosa et al. (2021) encontraram que os profissionais não contavam com oportunidades de crescimento profissional. Eles também eram expostos a situações de intimidação e submissão. Além disso, destacaram que muitos deles careciam de treinamentos organizados pela empresa de terceirização. Havia, ainda, dificuldades para mudanças de função. A ausência de vínculo direto com órgão público foi apontada pelos trabalhadores como causa do tratamento desigual que recebiam. No estudo de caso feito por Atayde (2021) em uma instituição pública, os trabalhadores terceirizados relataram condições de trabalho inadequadas. Eles também apontaram a existência de diferenças salariais em relação aos servidores públicos, a ausência de benefícios e a falta de oportunidades de crescimento na instituição. Isto trazia sentimentos de desvalorização e a sensação de serem descartáveis.

Tais dados mostram a urgência de se aprofundar a discussão sobre as consequências da terceirização para o trabalho, de modo a se pensar estratégias de promoção à saúde, de melhorias dos contextos laborais e, simultaneamente, de combater esta forma de precarização. Por sua vez, apesar da importância da delimitação de características comuns que circunscrevem o trabalho 
de profissionais terceirizados a partir das análises de dados oficiais e de informações estatísticas de determinados setores produtivos, é preciso ampliar a compreensão de como a terceirização ganha contornos singulares para categorias profissionais em contextos de trabalho específicos. Nesse sentido, são valiosos os estudos de caso ou os levantamentos que tratam de realidades locais.

Entretanto, quando se observam as pesquisas realizadas em instituições públicas de ensino, vê-se um enfoque predominante nos serviços de limpeza. É necessário, portanto, dar visibilidade à terceirização em outros setores, principalmente com o advento da Lei 13.429/2017 que expandiu a terceirização para as atividades fins, quando antes se limitava às atividades meio das empresas. A investigação aqui relatada se propôs a analisar o ofício e a saúde de trabalhadores terceirizados que atuavam no setor de almoxarifado de uma instituição pública de ensino.

Dados referentes ao ano em que o estudo foi realizado mostram que a instituição contava com 950 trabalhadores contratados por meio de empresas de terceirização e 3.458 técnico-administrativos concursados. A maior parte daqueles desempenhava atividades de limpeza, conservação, jardinagem, vigilância e portaria. $\mathrm{O}$ almoxarifado onde o estudo foi realizado tinha a função de acomodar produtos recebidos de diversos fornecedores contratados pelo órgão, além de realizar a distribuição destes em suas diversas unidades.

A fundamentação teórico-metodológica para a pesquisa veio da Clínica da Atividade, perspectiva que visa fortalecer a capacidade de os trabalhadores reencontrarem ações que os levem a um trabalho no qual seja possível reconhecer-se individual e coletivamente. Nesse sentido, o trabalhador se torna responsável pela história do ofício do qual toma parte. Para tanto, procurase mediar o encontro entre os profissionais e os recursos próprios de sua atividade, tais como o coletivo de trabalho, a atividade prescrita e os imprevistos. Neste processo não está em jogo uma expertise externa que observa, interpreta e prescreve boas práticas aos trabalhadores, contudo busca-se torná-los sujeitos da observação e da interpretação, donos do domínio sobre sua atividade (Clot, 2017).

O ofício, por sua vez, é constituído por quatro dimensões relacionadas, quais sejam, impessoal, interpessoal, transpessoal e pessoal. As tarefas prescritas, os instrumentos e equipamentos de trabalho, modelos de gestão e outros aspectos dizem respeito à dimensão impessoal. A dimensão interpessoal circunscreve as interações que ocorrem no trabalho: entre colegas, com as chefias, com usuários do serviço ou produto, dentre outras. A dimensão transpessoal, ou gênero profissional, corresponde a prescrições implícitas elaboradas e compartilhadas pelo coletivo de trabalho, modos de falar e agir que dão suporte à ação que são aprendidos no convívio cotidiano. Tem-se, por fim, a dimensão pessoal, ou estilo profissional. As prescrições do gênero também são submetidas às imprevisibilidades e às variações inerentes à atividade. Desta forma, o trabalhador recria gênero profissional já estabelecido a partir de suas experiências imediatas e, assim, desenvolve seu estilo pessoal ao mesmo tempo que pode contribuir com a renovação da dimensão transpessoal (Pinheiro et al., 2016).

A saúde é compreendida como potência de ação sobre o mundo, como capacidade de inventar novas normas diante do instituído (Clot, 2013). Nesse sentido, a atividade é saúde na medida em que a ação humana é um recurso para potencializar o poder de agir do indivíduo sobre o seu contexto, portanto, um meio de restauração das condições de reconhecer-se no que faz, usando de si e dos outros. Por outro lado, a atividade impedida rebaixa o poder de agir dos sujeitos, de modo que é possível perder a saúde antes mesmo de efetivamente adoecer (Souto et al., 2015).

\section{Metodologia}

A investigação apresentada é um estudo de caso (Yazan, 2015) realizado a partir de dados provenientes de uma intervenção da qual participaram trabalhadores terceirizados que atuavam no almoxarifado de um órgão público. Tal delineamento é coerente com a perspectiva da Clínica da Atividade, que propõe a realização da intervenção para que, posteriormente, seja efetivada uma pesquisa derivada de dados oriundos do processo interventivo. Os sujeitos e a necessidade 
de ampliar seu poder de agir encontram-se como foco da intervenção. Nesse sentido, enquanto a intervenção se orienta pelas questões elaboradas pelos trabalhadores, a pesquisa nasce de uma pergunta do pesquisador e possui objetivo científico, por isso essas duas etapas guardam momentos e temporalidades distintas (Gomes et al., 2015).

\subsection{Participantes}

O Almoxarifado contava com oito servidores públicos e dez trabalhadores contratados por meio de empresa de terceirização de mão de obra. Todos os trabalhadores participaram da intervenção, a despeito de os profissionais terceirizados serem enfocados nesta investigação. Neste grupo, sete eram encarregados de funções administrativas, tais como elaboração de inventários, controle de entrada e saída de produtos, avaliação de solicitações de materiais. Os demais - almoxarifes (4), carregadores (4), motoristas (2) e serviços gerais (1) - ocupavam-se com ações operacionais, dentre as quais a organização de materiais no estoque, a separação, o carregamento e o transporte de produtos para atender as requisições de cada setor da instituição.

\subsection{O Percurso da Intervenção}

A intervenção foi realizada por dois psicólogos do setor de gestão de pessoas da instituição e durou 12 meses. A demanda inicial pela intervenção partiu da chefia do setor e estava relacionada a dificuldades quanto aos processos de trabalho. Houve uma fase inicial de observações que visava analisar a atividade realizada e desenvolver no trabalhador a reflexão sobre a própria atividade, uma vez que, ao ser alvo do olhar do outro (analista do trabalho), o trabalhador torna-se observador de si e de sua própria atividade (Souto et al., 2015).

Em seguida, foram realizadas autoconfrontações, nas quais o trabalhador comenta um vídeo de suas atividades que foram previamente filmadas. A seleção das atividades registradas é feita em conjunto com os trabalhadores. Em um momento posterior, o sujeito comenta as filmagens das atividades de um colega que realiza tarefas similares e vice-versa. Ambas as situações são acompanhadas pelo mediador da intervenção. Ao confrontar-se com sua ação, o trabalhador observa-se como outro de sua própria atividade e, ao falar sobre ela, destinando esse enunciado a si, a outro e a sua própria atividade descrita, produz desenvolvimento e surgem novos modos de proceder (Roger, 2013). Em uma terceira etapa, as discussões produzidas retornaram ao coletivo, de modo a se tornarem ferramentas de ação e de modificação dos contextos de trabalho. Os debates suscitados pelas autoconfrontações foram sistematizados e rediscutidos com o grupo.

\subsection{Análise dos Dados}

Utilizou-se a análise construtivo-interpretativa (Rossato \& Martínez, 2018) sobre os conteúdos dos registros produzidos durante a intervenção (relatórios das observações, transcrições de autoconfrontações e de reuniões realizadas com os trabalhadores). Este procedimento pretende-se aberto, processual e não objetiva reduzir o conteúdo analisado a categorias concretas restritivas. Além disso, não se orienta para a produção de resultados universais e invariáveis, mas compreende suas conclusões como processos inscritos em uma realidade social e histórica. Foram construídas categorias relacionadas à remuneração e qualificação; equipamentos de trabalho e estrutura física; riscos laborais e assédio moral e instabilidade do vínculo trabalhista.

\subsection{Considerações Éticas}

O projeto foi apreciado pelo Comitê de Ética em Pesquisa da Universidade Federal do Ceará e autorizado sob o número CAAE 51047315.3.0000.5054, segundo todas as diretrizes e normas regulamentadoras descritas na Resolução 466 de 2012. Todos os nomes apresentados nos resultados são fíctícios. 


\section{Resultados e Discussão}

\subsection{Remuneração e Qualificação}

Iniciaremos a discussão com aspectos da dimensão impessoal do ofício. Trabalhavam no setor almoxarifes terceirizados e concursados. Apesar deste ser um cargo já extinto, ainda havia servidores públicos da ativa exercendo essa função. Observouse uma diferença de remuneração entre os profissionais, uma vez que os servidores públicos recebiam de três a quatro vezes mais que os terceirizados. Tal situação se coaduna com a indicação dada, por exemplo, por Druck (2016a), de que há diferenças salariais entre terceirizados e efetivos.

Outro aspecto importante é que os servidores públicos possuíam uma política de incentivo à qualificação com cursos sendo ofertados sistematicamente pela instituição e recebiam aumentos salariais ao realizá-los. Os terceirizados, por sua vez, caso precisassem fazer alguma formação deveriam procurá-la por conta própria, custeá-la com o próprio salário e não eram necessariamente recompensados por isso. O excerto abaixo ilustra essa situação:

\section{Moisés: eu tenho curso do MOPP [Movimentação e Operação de Produtos Perigosos], né?}

Lucas: ... ele [referindo-se ao Moisés] tem preparação e trabalha com o produto, mas só que, sinceramente, não é recompensado para isso, né? Ele fez o curso, trabalha com o produto, mas financeiramente não tem o retorno.

Como visto anteriormente, num modelo de trabalho precarizado, com o discurso da flexibilização, transfere-se a responsabilidade de qualificação para o trabalhador (Lima, 2010; de Magalhães et al., 2013). Percebe-se que não havia para os terceirizados um suporte institucional para desenvolvimento profissional e não havia perspectivas de ascensão na carreira.

\subsection{Equipamentos de Trabalho e Estrutura Física}

Havia queixas referentes a outros aspectos da dimensão impessoal do ofício, relativos à ausência de materiais adequados para o exercício das atividades. Os trabalhadores se viam obrigados a lidar com falta de caixas apropriadas para o transporte e o armazenamento de produtos, além de carrinhos com pneus desgastados ou com câmaras de ar furadas:

Carlos: era para ter, né, [uma caixa para cada pedido de material]? Ter caixa suficiente.

Facilitador: a caixa que vocês usam é tipo engradado de feira [com frestas nas laterais], né?

Sávio: até que eles pediram agora para ser fechada, porque estavam caindo as coisas que são pequenas.

Carlos: passa pela brecha.

...

Mário: os pneus, as câmaras de ar e mais dois carrinhos, né, que nós falamos para vocês também continuam do mesmo jeito [danificados]. Vieram só dois carrinhos. Nem os pneus nem as câmaras de ar chegaram.

Na medida em que os materiais caíam pelas frestas das caixas e se perdiam, havia inúmeras reclamações por conta de pedidos que chegavam incompletos aos setores. Os carrinhos danificados, por sua vez, faziam com que o trabalho fosse ainda mais exaustivo, já que dificultavam a movimentação de materiais pesados. Ruan, um dos almoxarifes terceirizados, relatou que, ao longo da intervenção, encontrou um pacote de sacos plásticos que não eram utilizados há muito tempo. Então, a partir das reclamações dos carregadores e da sua própria percepção sobre o problema das caixas, começou a utilizar esses sacos para guardar os itens das solicitações que eram pequenos (canetas, lápis, borrachas, corretivos, dentre outros). Nesse sentido, 
observou-se uma ampliação do poder de agir diante de um impedimento à atividade que logo foi incorporado à cultura do grupo, de modo a fortalecer o gênero profissional.

Em outro momento, os trabalhadores relataram problemas estruturais do galpão onde realizavam as atividades: falta de ventilação, estrutura velha e degradada e com poeira acumulada. A poeira presente no galpão era motivo de adoecimento recorrente. Os trabalhadores precisavam ausentar-se com frequência para tratamento de saúde e muitos voltavam a adoecer pelos mesmos motivos, como é possível ver no trecho a seguir:

Amorim: eu pego poeira demais ai embaixo [no galpão]. Peguei uma sinusite ... Fica tipo uma crise sabe? ... Quando eu vejo que está muito grave eu procuro um médico e fico de atestado ... Teve um dia que fiquei doente ... e peguei dois, três dias de atestado. Quando eu voltei não adiantou de nada: eu fiquei de novo doente.

Nas situações relatadas, além do impedimento ao poder de agir, havia consequências que levavam ao adoecimento propriamente dito. Vê-se, portanto, uma aproximação com outros estudos que apontaram uma associação entre a precarização das condições de trabalho e a terceirização (Andrade et al., 2016; Neves et al., 2013).

\subsection{Riscos Laborais}

Os funcionários do setor pesquisado estavam expostos a riscos decorrentes do armazenamento de material inflamável, como botijões de gás butano abastecidos, e da exposição a produtos tóxicos. Tal quadro pode ser observado no trecho abaixo, que menciona um acidente com um produto químico cuja origem os trabalhadores não conheciam e nem sabiam a forma correta de manuseio:

Ruan: estourou um produto químico que, no caso, afetou, né? Eu fui pegar ele, uma parte do produto com a mão, aí começou a queimar minha mão. A chinela do Amorim fumaçou. Eu lavei; rapidamente fui lavar a mão. Eu tive dor de cabeça e o rapaz que estava aí na limpeza já estava também com dor de cabeça. O objetivo era de querer limpar. A gente não sabe lidar com esses problemas. Tem que ter calma quando for abrir, tem muitas coisas aí que são químicas. Um risco para a saúde da gente.

Os profissionais com vínculo terceirizado não recebiam adicional de periculosidade, uma vez que no contrato firmado com a empresa de terceirização não havia previsão de verba orçamentária específica destinada para esta finalidade, enquanto os servidores públicos recebiam tal benefício. Eles sabiam do direito de receber o adicional de periculosidade e relataram que a solução seria acionar judicialmente a empresa de terceirização. Tal atitude acarretaria, entretanto, o risco de serem demitidos. Além disso, a partir do excerto, podemos observar que os trabalhadores não tinham treinamento ou orientação específica para prevenir ou lidar com acidentes.

A má conservação do galpão onde trabalhadores atuavam também favorecia o aparecimento de animais peçonhentos como cobras e escorpiões. No trecho abaixo, há o relato de uma colmeia cujas abelhas causaram danos a alguns trabalhadores:

Facilitadora: sobre os bichos que tem ai no galpão, que vocês falaram...

Ruan: A gente estava separando, aliás contando os materiais, num sábado extra que teve ... A gente foi contar e estavam lá as abelhas. Picou até o Gabriel. Ele foi tirar e foi picado. Pegaram ácido muriático e jogaram em cima delas lá. 
Podemos perceber como a improvisação, marca do trabalho precário, está presente no cotidiano desses profissionais, uma vez que a contratante (nesse caso, um órgão da administração pública) isenta-se das responsabilidades, especialmente para com as questões de saúde e riscos laborais, os quais passam a ser assumidos integralmente pelos próprios trabalhadores (Kalleberg, 2009). Segundo dados da SNRT (2014), trabalhadores com vínculo terceirizado sofrem 47\% mais acidentes laborais do que aqueles com vínculo efetivo. Os dois principais motivos para tanto são a ausência de treinamentos e as condições estruturais inadequadas, como podemos observar no caso estudado. Franco e Druck (2008) apontaram que a terceirização suscita riscos e responsabilidades sobre a saúde e a segurança dos trabalhadores, promove a fragilização das condições de segurança e ressaltam a "invisibilidade" dos acidentes devido às subnotificações.

\subsection{Assédio Moral e Instabilidade do Vínculo Trabalhista}

Uma questão relacionada à dimensão interpessoal do ofício se destacou ao longo da intervenção: os profissionais terceirizados passavam por diversas situações de desrespeito e preconceito, expressas em ameaças de advertência, de devolução para a empresa e até de desemprego, atitudes que partiam de uma das chefias. Os trabalhadores associavam esse gestor à representação de feitor, remetendo assim à noção de autoritarismo e abuso de poder. Os trabalhadores relataram que trabalhavam com medo e sofriam constrangimentos frequentemente. Eram constantes também as situações em que não se respeitavam os momentos de pausa e que eram obrigados, sem qualquer propósito, a desfazer o trabalho realizado no dia anterior, porque a chefia entendia que essa era uma forma de mantê-los ocupados.

\section{Facilitadora: como era que isso acontecia mesmo?}

Ruan: ... ele ameaçava qualquer um aqui, no caso, botar para fora; entregar para a empresa.

Eudes: ele ameaçava trocar [o empregado] por qualquer coisinha. Tinha que ficar calado, não podia nem responder, porque se fosse responder ele...

Amorim: porque aqui existe um certo preconceito com os terceirizados. Não sei se existe ainda, né? Porque essas pessoas que andavam aqui, que tinham muito preconceito com os terceirizados, deixaram de andar. Não sei se foi por conta da troca da chefia aqui, né? Mas ele vivia dizendo na cara de todo mundo que os terceirizados eram todos f... [palavra de baixo calão] aqui. Que não tinha que reclamar de nada. Dizia assim, na cara mesmo.

$[\ldots]$

Facilitador: e como é que vocês se sentiam com essas coisas dele?

Lucas: no mínimo constrangido, né? Intimidado, né?

Ruan: constrangido, né?

Moisés: a gente trabalhava com medo, né? Tinha muita gente que trabalhava com medo, né?

Nesse contexto, os relatos de desrespeito, humilhação e perseguições foram bastante destacados pelos trabalhadores, o que pode ser associado à prática de assédio moral, resultado que se aproxima daquele encontrado por Barbati et al. (2016). Segundo Barreto (2003), o assédio moral caracteriza-se por humilhação, constrangimento e situação vexatória no exercício da função. O assédio moral torna os trabalhadores mais vulneráveis e é caracterizado por rejeição deliberada ou sistemática pelos pares ou por níveis hierárquicos superiores. O assédio é importante fator de origem e/ou de desencadeamento de sofrimento psíquico e pode levar a quadros mais profundos de distúrbios psicológicos ou físicos.

Havia uma forte vinculação desse tipo de assédio à condição de terceirizado. Os trabalhadores relataram que as situações apresentadas no excerto acima despertavam sentimentos tais como constrangimento, medo, raiva, pois eles não tinham como 
"reagir/responder", devido à instabilidade do vínculo e à iminente possibilidade de perda do emprego que, em alguns relatos, surgiu como uma possibilidade ligada à vontade pessoal do gestor.

Selligman-Silva (2011) aponta para a desumanização do trabalho e para o desamparo, ambos presentes nas novas formas de gestão pelo medo, especialmente o medo do desemprego, por meio do qual o gestor, como observamos neste estudo, imprime uma nova forma de controle sobre os seus subordinados. O sofrimento mental, segundo a autora, tem sido ampliado ao dispersarem-se ameaças constantes aos trabalhadores como medida coercitiva comum entre gerentes, encarregados e chefias. No trecho a seguir percebemos a alta rotatividade - um dado marcante presente nas pesquisas desenvolvidas sobre a precarização laboral de trabalhadores terceirizados (SNRT, 2014) — quando Moisés se refere à troca constante de motoristas:

Moisés: Eles [os gestores] ficam só colocando os motoristas para fora. Eu que fiquei. O seu Eudes teve uma desavença aí com o Mário. O outro foi o Sávio, que passou por aqui também, aquele gordinho. Agora é ele aí, mas meu parceiro aí vai ficar, se Deus quiser.

Verifica-se a descartabilidade do trabalhador nesse contexto de terceirização. Segundo os participantes do estudo, o gestor responsável pelas demissões afirmava que qualquer um que ocupasse a função a exerceria da mesma forma, sem levar em consideração o conhecimento acumulado ao longo dos anos de experiência no setor. O mesmo gestor ainda afirmava que, independentemente do tempo de serviços prestados à instituição, o funcionário poderia ser reposto, caso ele, sendo chefe, assim bem entendesse:

Sávio: ele fala: "Eu não quero mais o Amorim, o Sávio, o Mário. Quero mais não. Quero trocar. Me arranje mais três para cá.... Pode ter dez anos aqui que eu boto para fora. O que entrar faz o serviço do mesmo jeito. Se não prestar, devolve também."

Tal atitude enfraquecia a dimensão transpessoal do ofício, na medida em que dificultava a construção de uma cultura profissional compartilhada. A rotatividade e a descartabilidade são impeditivas ao desenvolvimento e ao fortalecimento do coletivo de trabalho. Na história de um ofício há um componente da formação profissional que requer uma experiência que só se aprende ao longo do tempo, através da construção de um repertório de ações que possibilita dar a resposta "certa" às necessidades dos imprevistos. Tal repertório é derivado da contínua interação com o cotidiano de trabalho no curso da atividade, o que é indispensável para a apreensão dos elementos que compõem e formam o gênero profissional.

\section{Considerações Finais}

A pesquisa teve como objetivo analisar o ofício e a saúde de trabalhadores terceirizados. Foi realizado um estudo de caso a partir de dados provenientes de uma intervenção em Clínica da Atividade que aconteceu no setor de almoxarifado de uma instituição pública de ensino. Os resultados indicaram diferenças de remuneração e de benefícios entre trabalhadores terceirizados e servidores públicos que exerciam a mesma função. Também foi observada uma situação laboral permeada por vulnerabilidades, riscos à saúde e à segurança, pois os trabalhadores atuavam em condições inadequadas, como ambiente empoeirado, mal iluminado e sem ventilação, com estrutura precária e antiga e expostos a produtos perigosos. Constatou-se, ainda, carência de materiais em boas condições e uso de equipamentos inapropriados. Também eram marcantes o autoritarismo e as atitudes centralizadoras de um gestor, o que reduzia a autonomia dos trabalhadores e os submetia a situações vexatórias. Vêse, por conseguinte, que esses profissionais estão sujeitos a acidentes, doenças, assédio, ameaças, desrespeito e preconceito devido a condição de trabalho precarizada. 
A pesquisa aborda categorias profissionais que não são comumente visadas quando se estuda a terceirização em instituições públicas de ensino. Além disso, na medida em que os dados utilizados no estudo vêm de uma intervenção cujo foco era a promoção da saúde dos trabalhadores, ampliação do poder de agir nos termos da Clínica da Atividade, aumenta-se a possibilidade de que elementos que estão implícitos no cotidiano possam vir à tona e revelar questões importantes sobre a precarização laboral. O contato aprofundado que os facilitadores mantêm com os profissionais, a densidade das discussões realizadas e a tentativa deliberada de problematizar o cotidiano de trabalho, de modo a construir encaminhamentos para as dificuldades enfrentadas, leva a um reposicionamento dos trabalhadores diante de sua atividade que abre a possibilidade para o surgimento de questões que ficariam ocultas na utilização de métodos diretos de coleta de dados, como entrevistas e grupos focais.

Por outro lado, esta mesma característica também implica em limitações, pois, os dados construídos estão restritos às produções do grupo de trabalho ao longo da intervenção. Na medida em que não há uma intenção de coleta de informações durante a intervenção e como também não existe uma delimitação prévia de pergunta de partida que oriente o recorte a ser dado, restringe-se a possibilidade de abordar temas de interesse específico.

Os resultados do estudo dão margem para várias possibilidades de investigações futuras. Analisar as interações entre trabalhadores contratados diretamente, no caso específico, servidores públicos e terceirizados permitiria compreender como se dá a dinâmica das relações profissionais em um contexto de precarização laboral. Também seria relevante analisar, especificamente, a incidência de assédio moral em trabalhadores terceirizados, bem como suas consequências para a saúde. Mostra-se relevante, ainda, comparar as experiências laborais entre categorias de trabalhadores terceirizados, de modo a delimitar as diferenças e semelhanças experimentadas em um contexto de precarização.

\section{Referências}

Andrade, M. de O., Cunha, V. S. da, Lins, W. de M. S., Yung, F. R., Abdon, J. A. S., \& Souza, E. M. de. (2016). Saúde ocupacional e riscos psicossociais em trabalhadores da limpeza de instituição de ensino superior: Um estudo qualitativo em Brasília, DF. Tempus - Actas de Saúde Coletiva, 10(1), 143-156. https://doi.org/10.18569/tempus.v10i1.1859.

Antunes, R. (1999). O mundo precarizado do trabalho e seus significados. Cadernos de Psicologia Social do Trabalho, 2, 55-59. https://doi.org/10.11606/issn.1981-0490.v2i0p55-59.

Aquino, C. A. B. (2008). O Processo de precarização laboral e a produção subjetiva: Um olhar desde a psicologia social. O Público e o Privado, 6(11), 169-178. https://revistas.uece.br/index.php/opublicoeoprivado/article/view/2383

Atayde, R. A. de A. (2021). O trabalhador terceirizado e a percepção da precarização do trabalho: Um estudo de caso em uma instituição pública brasileira. Revista Da Defensoria Pública Da União, (16), 221-240. https://doi.org/10.46901/revistadadpu.i16.p221-240.

Barbati, V. M., Henriques, F. C., Guimarães Junior, S. D., \& Ferreira, J. B. O. (2016). Capturas e resistências à terceirização: Estudo com trabalhadores de uma universidade pública. Revista Trabalho (En)Cena, 1(2), 110-127. https://sistemas.uft.edu.br/periodicos/index.php/encena/article/view/2925

Barbosa, M., Vieira, E. T., \& Dos Santos, M. J. (2021). Trabalhadores terceirizados da área meio no âmbito da administração pública federal: Assimetrias sociais e precarização. Latin American Journal of Business Management, 12(2). https://www.lajbm.com.br/index.php/journal/article/view/679.

Barreto, M. (2003). Violência, Saúde e Trabalho: Uma Jornada de Humilhações. Educ.

Batista, F. E. A., Soares Junior, G.., \& Oliveira, I. F. (2021). Precariousness, flexibility, and labor relations in the Fashion Industry. Research, Society and Development, 10(1), e11510110841. https://doi.org/10.33448/rsd-v10i1.10841.

Berni, L. B., Beck, C. L. C., Prestes, F. C., Silva, R. M. da, Bublitz, S., \& Lamb, F. (2016). Indicadores de prazer/sofrimento em trabalhadores terceirizados de higiene e limpeza de um hospital universitário. Revista da Rede de Enfermagem do Nordeste, 17(2), 155-164. https://doi.org/10.15253/21756783.2016000200002 .

Clot, Y. (2017). Clínica da Atividade. Horizontes, 35(3), 18-22. https://doi.org/10.24933/horizontes.v35i3.526.

Clot, Y. (2013). O ofício como operador de saúde. Cadernos de Psicologia Social do Trabalho, 16(spe1), 1-11. https://doi.org/10.11606/issn.19810490.v16ispe1p1-11.

de Magalhães, Y. T., Magalhães, M. G. S., Saraiva, L. A. S., \& Brasil, E. R. (2013). Qualificação de terceirizados em um contexto de múltiplos vínculos contratuais: Um desafio. Qualitas Revista Eletrônica, 14(1), 1-14. http://dx.doi.org/10.18391/qualitas.v14i1.1536

Druck, G., \& Borges, Â. (2002). Terceirização: Balanço de uma década. Caderno CRH, 15(37), 111-139. https://doi.org/10.9771/ccrh.v15i37.18604. 
Druck, G., Sena, J., Pinto, M. M., \& Araújo, S. (2018). A terceirização no serviço público: Particularidades e implicações. In Campos, A. G. (Org.), Terceirização do trabalho no Brasil: novas e distintas perspectivas para o debate (pp. 113-141). Ipea.

Druck, G. (2011). Trabalho, precarização e resistências: Novos e velhos desafios? Caderno CRH, 24(spe1), 37-57. https://doi.org/10.1590/S010349792011000400004.

Druck, G. (2016a). A indissociabilidade entre precarização social do trabalho e terceirização. In Teixeira, M. O., Rodrigues, H., \& Coelho, E. D. (Orgs.), Precarização e terceirização: Faces da mesma realidade (pp. 35-58). Sindicato dos Químicos-SP.

Druck, G. (2016b). A terceirização na saúde pública: Formas diversas de precarização do trabalho. Trabalho, Educação e Saúde, 14, 15-43. https://doi.org/10.1590/1981-7746-sol00023.

Druck, G. (2016c). Unrestrained outsourcing in Brazil: More precarization and health risks for workers [A terceirização sem limites: mais precarização e riscos de morte aos trabalhadores]. Cadernos de Saúde Pública, 32. https://doi.org/10.1590/0102-311X00146315.

Franco, T., \& Druck, G. (2008). O trabalho contemporâneo: Precarização e saúde mental. In Seminário Nacional de Saúde Mental e Trabalho, São Paulo: Fundacentro.

$\% 20$ Trabalho\%20contempor\%C3\%A2neo.pdf.

Gemma, S. F. B., Rojas, M. F., \& Soares, M. J. B. (2017). Agentes de limpeza terceirizados: Entre o ressentimento e o reconhecimento. Revista Brasileira de Saúde Ocupacional, 42(4), 1-10. https://doi.org/10.1590/2317-6369000006016.

Gimenez, D. M., \& Krein, J. D. (2016). Terceirização e o desorganizado mercado de trabalho brasileiro. In Teixeira, M. O., Rodrigues, H., \& Coelho, E. D. (Orgs.), Precarização e terceirização: Faces da mesma realidade (pp. 17-36). Sindicato dos Químicos-SP.

Guimarães Junior, S. D., \& Ferreira, J. B. de O. (2018). Sujeito em terceiro plano: Uma reflexão crítica acerca da articulação entre a dinâmica da terceirização e processos de subjetivação. Revista Psicologia Organizações e Trabalho, 18(2), 381-389. https://doi.org/10.17652/rpot/2018.2.14177.

Kalleberg, A. L. (2009). Precarious Work, Insecure Workers: Employment Relations in Transition [Trabalho Precário, Trabalhadores Inseguros: Relações de Trabalho em Transição]. American Sociological Review, 74(1), 1-22. https://doi.org/10.1177/000312240907400101.

Lima, J. C. (2010). A terceirização e os trabalhadores: Revisitando algumas questões. Cadernos de Psicologia Social do Trabalho, $13(1)$, 17. https://doi.org/10.11606/issn.1981-0490.v13i1p17-26.

Marcelino, P., \& Cavalcante, S. (2012). Por uma definição de terceirização. Caderno CRH, 25(65), 331-346. https://doi.org/10.1590/S010349792012000200010

Marcelino, P. R. (2007). Afinal, o que é terceirização? Em busca de ferramentas de análise e de ação política. PEGADA - A Revista da Geografia do Trabalho, 8(2), 55-71. https://doi.org/10.33026/peg.v8i2.1640.

Neves, B. C., Jesus, G. J., \& Soler, Z. A. S. G. (2013). Transtorno psíquico em trabalhadores terceirizados de limpeza e vigilância. Enfermagem Brasil, 12(4), 233-240. https://doi.org/10.33233/eb.v12i4.3759.

Pelatieri, P., Camargos, R.C., Ibarra, A., \& Marcolino, A. (2018). Terceirização e precarização das condições de trabalho: Condições de trabalho e remuneração em atividades tipicamente terceirizadas e contratantes. In: Campos, A. G. (Org.), Terceirização do trabalho no Brasil: Novas e distintas perspectivas para o debate (pp. 11-31). Ipea.

Pinheiro, F., Costa, M. F. V., Melo, P. B., \& Aquino, C. A. B. (2016). Clínica da Atividade: Conceitos e fundamentos teóricos. Arquivos Brasileiros de Psicologia, 68(3), 110-124. http://pepsic.bvsalud.org/scielo.php?script=sci_arttext\&pid=S1809-52672016000300009

Roger, J. L. (2013). Metodologia e métodos de análise em clínica da atividade. Cadernos de Psicologia Social do Trabalho, 16(spe), 111-120. http://pepsic.bvsalud.org/scielo.php?script=sci_arttext\&pid=S1516-37172013000300011\&lng=pt\&tlng=pt.

Rossato, M., \& Martinez, A. M. (2018). Contribuições da metodologia construtivo-interpretativa na pesquisa sobre o desenvolvimento da subjetividade. Revista Lusófona de Educação, 40(40), 185-198. https://doi.org/10.24140/issn.1645-7250.rle40.04.

Secretaria Nacional de Relações de Trabalho (2014). Terceirização e desenvolvimento: Uma conta que não fecha. Central Única dos Trabalhadores.

Seligmann-Silva, E. (2012). Trabalho e desgaste mental: O direito de ser dono de si mesmo. Cortez.

Souto, A. P., Lima, K. M. N. M., \& Osório, C. (2015). Reflexões sobre a metodologia da clínica da atividade: Diálogo e criação no meio de trabalho. Laboreal, 11(1), 20-50. https://doi.org/10.4000/laboreal.3962.

Yazan, B. (2015). Three Approaches to Case Study Methods in Education: Yin, Merriam, and Stake [Três abordagens para métodos de estudo de caso em educação: Yin, Merriam e Stake]. The Qualitative Report, 20(2), 134-152. https://doi.org/10.46743/2160-3715/2015.2102. 